\title{
The Influence of Intrinsic and Extrinsic Motivation in Public Universities in Ghana
}

\author{
Frederick Kwaku Sarfo, Michael Kofi Adu, Sabina Koompong, Abraham Attoh, Philip Baidoo* \\ Human Resource Department, Akenten Appiah-Menka University of Skills Training and Entrepreneurial Development, Kumasi, Ghana \\ Email address: \\ Sarfofredk2001@yahoo.com (F. K. Sarfo),mkadu65@gmail.com (M. K. Adu),skoompong@gmail.com (S. Koompong), \\ attohbarclay@yahoo.com (A. Attoh),mypennich@yahoo.com (P. Baidoo) \\ ${ }^{*}$ Corresponding author
}

\section{To cite this article:}

Frederick Kwaku Sarfo, Michael Kofi Adu, Sabina Koompong, Abraham Attoh, Philip Baidoo. The Influence of Intrinsic and Extrinsic Motivation in Public Universities in Ghana. American Journal of Operations Management and Information Systems.

Vol. 6, No. 3, 2021, pp. 58-66. doi: 10.11648/j.ajomis.20210603.14

Received: April 6, 2021; Accepted: April 19, 2021; Published: August 31, 2021

\begin{abstract}
The subsistence and development of every Institution and organization, to a large extent, depends on the employees' output. Therefore, it is authoritative for employers to make room for the satisfaction of employees in order to retain their due services. The purpose of the study was to examine the effects of intrinsic and extrinsic motivation on staff retention at Public Universities in Ghana (PUG). Primary data was collected from a total number of eighty (80) respondents comprising junior staff, senior staff, and senior members from PUG using structured questionnaires and interview guide to establish both extrinsic and intrinsic motivational factors that encourage staff retention on their job. Consequently, both quantitative and qualitative data were used. The influence of intrinsic and extrinsic motivation in PUG was characterized and analyzed to generate frequencies and percentages with the help of Microsoft Excel. The research findings showed that salary/wages, promotion, leave and health benefits, job security, accommodation, and transportation were the topmost variables that encourage employees extrinsically to remain on their jobs. There are lots of intrinsic and extrinsic motivational factors in the Public Universities of Ghana. However, the staff does not have intentions to see the downfall of their employer. In order to improve staff motivation at the Public Universities in Ghana, the finding factors have been indicated in the writeup.
\end{abstract}

Keywords: Intrinsic, Extrinsic, Motivation, Universities, Recognition, Respondents

\section{Introduction}

The accomplishment of any institution and organization is extremely dependent on its human resource. There are other factors that account for the accomplishment of an institution. The institution must have effective employees in order to stay in business. In order to maintain this all-important commodity, organizations must be aware of employee satisfaction and retention. Organizations must have and retain employees who are able to quickly come to terms and adapt in an ever-changing world. High productivity is a long-term benefit of employee motivation. In this era of transformation, the concern over employee's motivation is on the top of public management research agenda [1]. According to organizational and institution researchers: [2-4] people are the most important institutional resource and the key to achieving higher performance. [5] argued that public administration needs to reframe the question of motivation. Thus, it seems that in the dawn of a new century, the central challenge for public managers is to meet their institutions' objectives for effectiveness and increased productivity, while fulfilling the needs of employees for motivation, reward, and satisfaction. Motivation is operationally defined as, an inner force that drives individuals to accomplish personal and organizational goals with regards to an institution or an organization that one is attached to. However, motivation is the key to performance improvement. This assertion is supported by Castaing [6] that employees will do what they have to do and remain at the post if they are highly motivated. He then added that to be effective, managers need to understand what motivates employees within the context of the roles they play. Motivating employees is arguably the most complex undertaking. This is because what motivates one employee may not motivate the other. [7] discoursed that 
as 'employees' income increases, money becomes less of motivator and also, when employees get older, interesting work becomes more of a motivator. Motivation is "the psychological processes that cause the arousal, direction, and persistence of voluntary actions that are goals directed". Again, the desire within a person causing that person to act. However, people usually act for one reason; to achieve a goal.

Tertiary Education in Ghana started in the 1940s with the establishment of the University of the Gold Coast, now known as the University of Ghana. The main purpose for the establishment of the University was to provide for and promote University education, learning, and research. Currently, there are more than sixty-four (64) public Tertiary Institutions in Ghana supervised by the Ghana Tertiary Education Commission (GTEC). However, the researchers intended to focused on earlier-establishments of twentyseven (27) ones of which ten (10) were Public Universities; Eight (8) were Technical Universities; Nine (9) were Professional Public Universities. The level of motivation of Public University Employees remains central to the performance of their duties and the level of the academic ladder they have climbed. Detailing the checks on levels of intrinsic and extrinsic motivation per persons were ineffectual. Rather, the motivational culture addresses motivational deficiency needs. These constitute the needs like security in the job, reasonable pay, and opportunities for growth, promotions, and recognition. However, this influenced the researchers to investigate both intrinsic and extrinsic motivational factors that influence workers to stay on their jobs at the Public Universities in Ghana (PUG). Intrinsic motivation reflects an engagement in activities that are performed with the sole end being satisfaction. An intrinsically motivated employee would do things simply for the sheer joy of doing things and assessing results. Tangible rewards are not the ends that they drive toward achievement. According to Malone and Leper [8], intrinsic motivation is "what people do without external inducement". Hunger, a sense of duty, altruism, and a desire to feel appreciated are examples of intrinsic motivation. On the other hand, extrinsically motivated behaviors are those where the controlling mechanism is easily seen [9]. Extrinsic motivation has typically been characterized as a pale and impoverished (even if powerful) form of motivation that contrasts with intrinsic motivation [10]. An extrinsically motivated employee is driven by tangible rewards - money, gifts, social approval; or they are driven specifically to avoid punishments - getting fired, rejection, being passed over for an important project, and career-limiting responses. [11] stated that employers usually administer rewards in them, form of praising a committed employee, provision of fringe benefits and recognition. According to [11] the intrinsic rewards are self-administered. They consist of how employees feel about an objective accomplished. Attention is being drawn here to the fact that behavior stems from within an individual. The individual is directed towards a goal and that which will help boost the image as well as increasing performance. It is essential to consider the needed characteristics of individual employees before looking at them as a group. Intrinsic motivation is a positive internal feeling which is independent of outside rewards. Extrinsic motivation on the other hand is the feeling which an individual gets externally and not characterized by inward rewards. Every business establishment strives to increase performance to reflect productivity through employee's contribution. It has always been a bother to ascertaining what would serve as a boost to employees to give a total commitment to an Institutions' objective and to stay on their jobs. As pointed out by [12], there is no simple knowledge about motivation, and that most supervisors need to equip themselves with theories that social scientists have proposed. However, it has been admitted that none of these theories is up to perfection or has proven explanations of how to get employees to behave in a certain way. It should however be stated that they all give supervisors some guidance and even equip them to think of ways to motivate employees. [13], influenced by Maslow and McGregor put forward his own theory of motivation called motivation-hygiene factors. He describes two dimensions of conditions: motivators and hygiene factors. Motivators, similar to Maslow's higher-level needs, are what lead to job satisfaction and are associated with the nature of the work itself; achievement, recognition, responsibility, and growth. Motivators are intrinsic and simply reduce job satisfaction. Examples of hygiene factors include salary, interpersonal relations, company policies and administration, status, working conditions, and job security. For instance, an employee can have a high salary or incentives (extrinsic hygiene factor) and great work conditions, leaving his not dissatisfied. However, if his job is not rewarding and he does not feel challenged in the tasks he does, then she may not be very satisfied and thus not motivated. However, the effect of motivation on the longterm health and success of any institution depends upon the retention of key employees. Encouraging employees to remain in the institution for a long period of time can be termed as employee retention. [14] viewed retention as "an obligation to continue to do business or exchange with a particular company on an ongoing basis". Clearly, those employees who are happy and satisfied with their jobs are more dedicated towards their work and always put in their effort to improve their institutional customers' satisfaction. According to Daniel Gberevbie (2010), [14], it is becoming more essential to secure and manage the competent human resource as the most valuable resource of any institution and organization, because of the need for effective and efficient delivery of goods and services by institutions, whether public or private sector. Therefore, for an institution to realize its goals, appropriate strategies for employee recruitment and retention are sine-qua-non for enhanced performance.

\section{Methodology}

The research design adopted for the study was the descriptive design. A research design was defined by $[15,16]$ 
as a plan for conducting research, which normally the specification of the elements to be examined and the procedures to be used were detailed during the process. It refers to the overall plan the researcher employs to collect data in order to answer the research questionnaires. It is a researcher's blue-print which indicates how data was collected and analyzed. Descriptive research studies are designed to obtain information concerning the current states of phenomena. They are directed towards determining the nature of things as they exist at the time of the study. The descriptive research was deemed appropriate for the study as the researchers intended obtaining the views of the respondents with regards to the effect of intrinsic and extrinsic motivation on employee performance as they pertain at the time of the study. The primary data was obtained through a structured questionnaire. The questionnaire was designed for senior members, senior staff, and junior staff of PUG to investigate their views on the effect of intrinsic and extrinsic motivation on staff retention. Out of the total population of 399 , a sample size of 100 , being $25 \%$ of the total population, was selected for the study. The stratified proportional sampling was used to allocate the number of respondents to be selected from each stratum. The stratified sampling method is used where the population is heterogeneous or of varied characteristics such that, a simple random sample may not be representative of all the varied groups in the population. Therefore, the population is divided into smaller segments, based on the different characteristics. Since the researchers wanted the various groups (strata) to be represented in the study, the technique was deemed necessary.

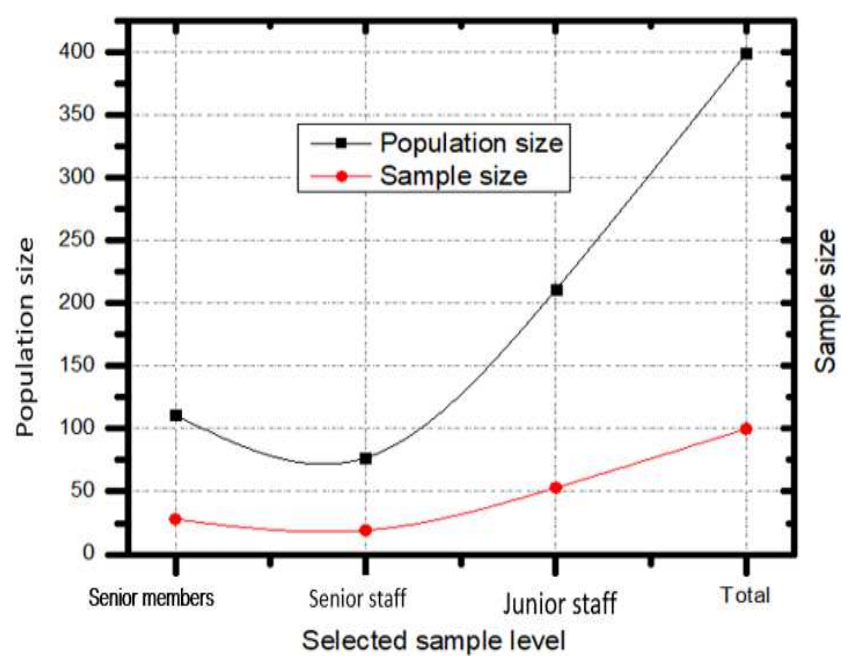

Figure 1. Breakdown of the selected sample size for the study.

After getting the proportion to select from each stratum, the Simple Random Sampling technique was used to select the actual members from each stratum.

The main instrument used to collect data from the Senior Members, Senior Staff and Junior Staff was questionnaire. The questionnaires were distributed to all selected members in the various strata. The questionnaire was pre-tested at Christian Service University. The test yielded a reliability coefficient of 0.89 using Cronbach alpha reliability. The analysis of data was done at the end of the data collection. The responses were grouped and categorized on the basis of information provided using Statistical Package for Social Sciences (SPSS) version 16 to analyze the data. The data was analyzed using descriptive statistics, namely the mean, standard deviation, frequency and where applicable graphs and tables were used for illustrations. Regression and correlation analysis were also carried out to establish the relationship between motivation and staff retention. The analysis was based on the mix method, that is both quantitative and qualitative methods were used. The questionnaire was analyzed quantitatively while the interview responses were analyzed qualitatively.

\section{Results and Discussions}

\subsection{Results}

This work presents the analysis of the responses given by the respondents under the study. Of the 100 questionnaires sent, 80 questionnaires were returned for analysis, representing $80 \%$ and questionnaires majority safe of $20 \%$. Response rate Data was collected from 80 subjects made up of 42 males and 38 females. The analysis was done, using percentages, frequency counts and mean. The analysis was done based on the research questions. The chapter has been divided into two (2) main parts - analysis of the results and discussion of the findings.

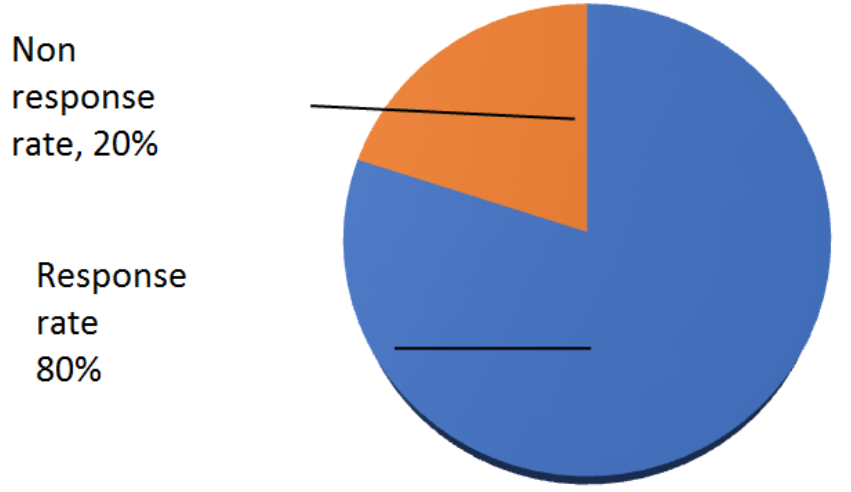

Figure 2. Response rate.

\subsubsection{Personal Characteristics of Respondents}

The demographic characteristics were established to know the nature of the respondents who participated in the study as related to their gender, age and marital status. The summary is represented in table 1, figures 2 and 3, respectively.

Table 1. Personal Characteristics of Respondents.

\begin{tabular}{lll}
\hline Response & Frequency & Percentage (\%) \\
\hline Gender & & \\
Male & 42 & 52.5 \\
Female & 38 & 47.5 \\
Total & 80 & 100 \\
\hline
\end{tabular}

Source: Fieldwork, 2020. 
From table 1 it is evident that $52.5 \%$ of the respondents were males while $47.5 \%$ were females. The majority of the respondents that accounted for $75 \%$ were between the ages of 20 - 40 while $25 \%$ were above 40 years.

However, from figure 2, it is revealed that persons aged between 31-40 representing 38.8\% had a higher percentage being employed in the university setups in PUG, whiles ages 50 and above, representing $7.5 \%$ were lesser employed in the PUG. This implied that majority of personnel have long service life before retirement. Hence, they can render longer service contribution to the development of the PUG.

Figure 3, indicates the marital status of the respondents. More than half $(53.2 \%)$ of the respondents were married. 33 ( $41 \%$ ) out of the 80 respondents were single, $3(3.8 \%)$ of the respondents out of 80 were divorced and only $1(1.3 \%)$ was separated.

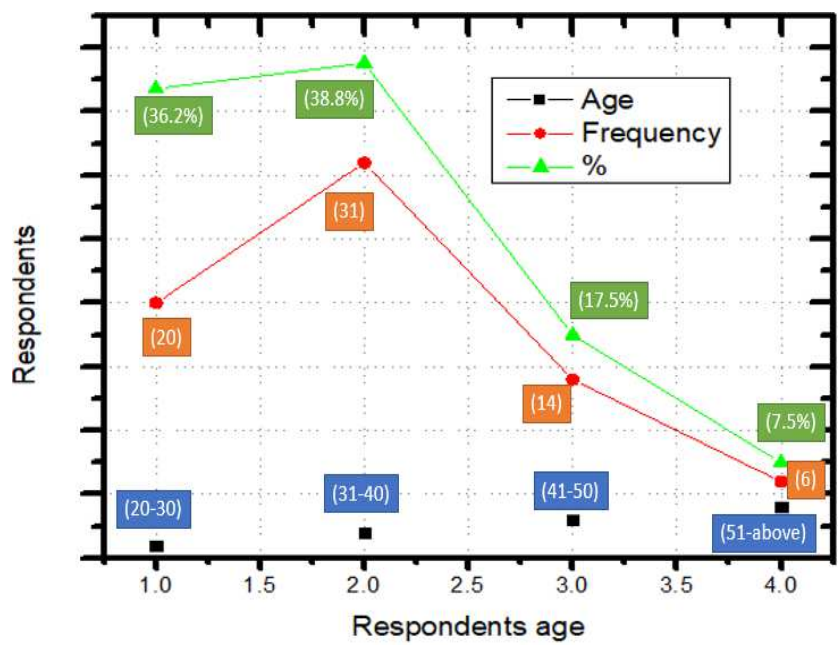

Figure 3. Personal Characteristics of Respondents and ages.

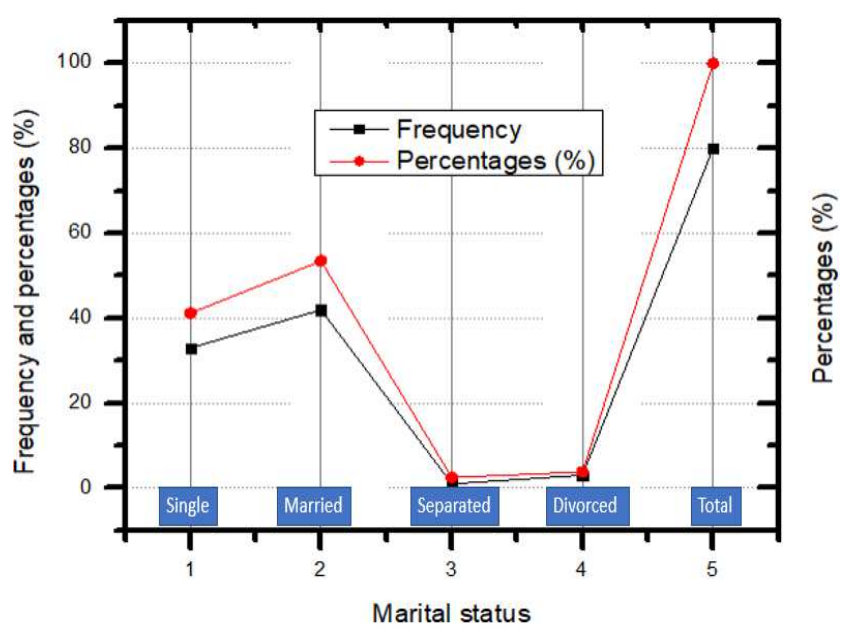

Figure 4. Personal Characteristics of Respondents and marital status.

\subsubsection{Occupational and Educational Characteristics of Respondents}

The occupational and educational variables of the respondents were also ascertained in the study. Table 2 presents the analysis of the occupation of the respondents.
Table 2. Occupational and Educational Characteristics of Respondents.

\begin{tabular}{lll}
\hline Response & Number & Percentage (\%) \\
\hline Status/Rank & & \\
Senior Members & 28 & 35 \\
Senior Staff & 34 & 42.5 \\
Junior Staff & 18 & 22.5 \\
Total & 80 & 100 \\
\hline
\end{tabular}

Source: Fieldwork, 2020.

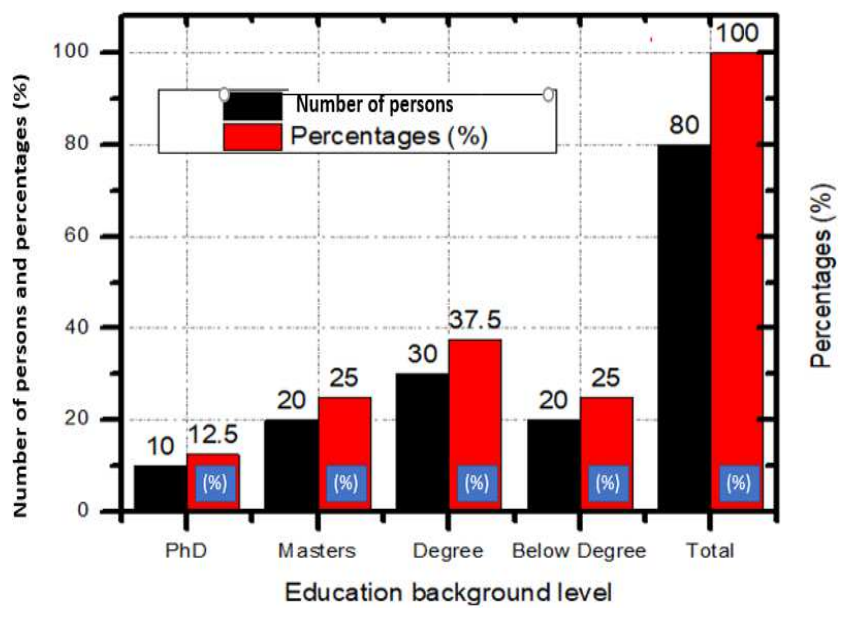

Figure 5. Education background and Percentage (\%).

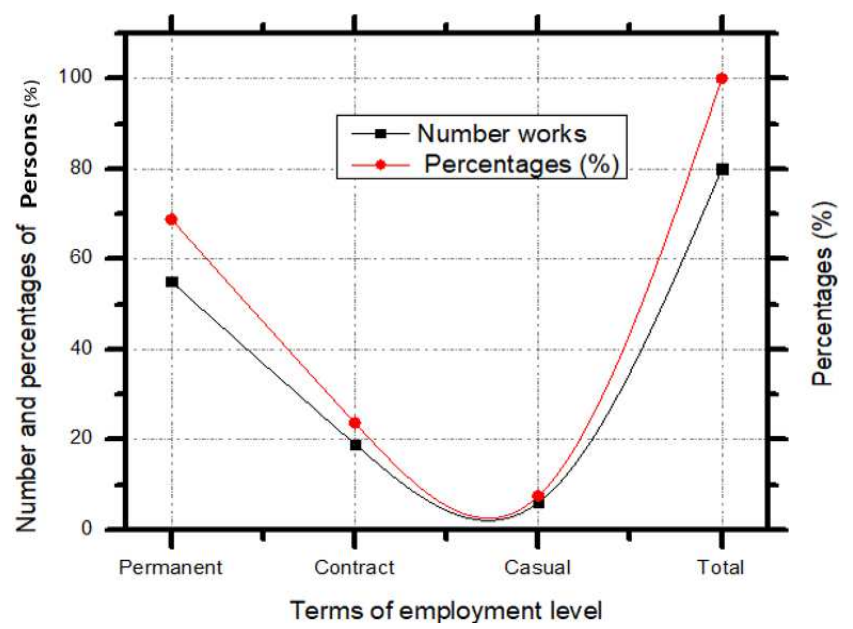

Figure 6. Number of types of employment and percentage (\%).

As regards to respondents' status, 34 members of $42.5 \%$ representing the higher number of staff used for the studies were senior staff, whilst 28 respondents that accounted for $35 \%$ were also senior members. Again, 18 of the respondents being minority representing $22.5 \%$ were junior staff. As regards terms of employment, Figure 6 above, indicates that $68.8 \%$ of the respondents were permanent workers whilst $23.7 \%$ and $7.5 \%$ were on contract and casual appointment, respectively.

It is also depicted in figure 5 above that 30 respondents, accounting for $37.5 \%$ had $1^{\text {st }}$ degree, $25 \%$ had $2^{\text {nd }}$ degree and $12.5 \%$ had $3^{\text {rd }}$ degree qualifications respectively. On the other hand, $25 \%$ of the respondents had a qualification below $1^{\text {st }}$ Degree. 


\subsubsection{Extrinsic Motivational Factors That Encourage Employee Retention}

This research question was designed to determine the type(s) of extrinsic motivational factors that encourage employee satisfaction and retention at PUG. The type of extrinsic motivations that a person receives at the work place to a greater extent determines the level of employee satisfaction and retention. Responses to this question are presented in table 3 below.

Table 3. Extrinsic motivational factors that encourage employee retention.

\begin{tabular}{|c|c|c|c|c|c|c|c|}
\hline \multirow{2}{*}{ Extrinsic motivational factors } & \multicolumn{5}{|c|}{ Number/Frequency } & \multirow{2}{*}{$\bar{x}$} & \multirow{2}{*}{ Decision } \\
\hline & 5 & 4 & 3 & 2 & 1 & & \\
\hline Salary, wages (money) & $(14.0)$ & $(15.0)$ & $(13.0)$ & $(23.0)$ & $(25.0)$ & 2.9 & Agree \\
\hline Promotion & $(34.0)$ & $(21.0)$ & $(7.0)$ & $(8.0)$ & $(10.0)$ & 3.3 & Agree \\
\hline Position & $(31.0)$ & $(32.0)$ & $(8.0)$ & $(7.0)$ & $(2.0)$ & 4.0 & Agree \\
\hline Leave benefits (maternity, sick) & $(22.0)$ & $(28.0)$ & $(8.0)$ & $(12.0)$ & $(10.0)$ & 3.5 & Agree \\
\hline Retirement plan & $(12.0)$ & $(15.0)$ & $(14.0)$ & $(22.0)$ & $(17.0)$ & 2.8 & Agree \\
\hline Health and other benefits & $(45.0)$ & $(19.0)$ & $(7.0)$ & $(13.0)$ & $(6.0)$ & 3.8 & Agree \\
\hline Good safety measures & $(18.0)$ & $(27.0)$ & $(13.0)$ & $(10.0)$ & $(12.0)$ & 3.4 & Agree \\
\hline Job security & $(16.0)$ & $(41.0)$ & $(11.0)$ & $(15.0)$ & $(17.0)$ & 3.2 & Agree \\
\hline Accommodation and transportation & $(23.0)$ & $(29.0)$ & $(19.0)$ & $(10.0)$ & $(19.0)$ & 3.1 & Agree \\
\hline
\end{tabular}

Source: Fieldwork, 2020.

Note: 5=Very Important, 4= Somewhat Important, 3 = Neutral, 2= Not very important, 1=Not at all important) x $(1.00-2.50-$ Disagree; $2.6-5.00-$ Agree).

The table 3 shows the responses given by the respondents to the items "what motivational factors encourage employee retention". In all, 10 items were constructed to find solution to the research question. Item 1 was on salary and wages. This item received a mean rank of 2.9. This implies that the respondents were of the view that monetary factor accounts for employee retention in the PUG.

As regards promotion, 34 representing $42.5 \%$ of the respondents indicated that it is very important, 21 accounting for $26.3 \%$ also indicated somewhat important response, 7 indicated neutral, 8 were of the view that it is not very important and 10 were of the view that it is not at all important. The item recorded a mean rank of 3.3. This implies that promotion is one of the extrinsic factors that account for employee retention. Table 3 further shows that 31 of the respondents indicated that position is a very important extrinsic factor that motivates staff retention. Thirty-two (32) of the respondents indicated somewhat important, accounting for $40 \%$ of the respondents, 8 were undecided, 7 indicated very important and 2 indicated not all important. However, the item had a mean ranking of 4.0 which indicates that position is an important extrinsic factor that needs to be given attention in employee retention.

With regard to leave benefits, 22 staff, representing $27.5 \%$ indicated that it was very important. Again, 28 staff that accounted for $35 \%$ of the respondents, pointed out that it was somewhat important. 8 were neutral, whilst 12 answered that it was not very important, and 10 viewed benefits as not at all important. The mean rank of 3.5 indicated that leave benefits is one of the important extrinsic factors that lead to employee retention.

On the issue of retirement plan, 12 representing $15 \%$ of the respondents, chose very important. 15 (18.8\%) chose somewhat important, 14 were neutral, 22 chose not very important while 17 indicated not at all important. The item recorded a mean rank of 2.8 which implies that the respondents were of the view that retirement plan is a necessary factor in determining if an employee will remain in the employment.

Health and other benefits had a mean rank of 3.8 which indicates that good health plan and other benefits employees receive account for the employee retention in the Institution. Forty-five (45) accounting for $56.3 \%$ of the respondents indicated that health and other benefits were very important to employee retention whilst 7 and 6 respondents accounting for $8.8 \%$ and $7.5 \%$, respectively, indicated that health and other benefits were not their concern and not at all important to their retention at their work place.

As regards career opportunity for mobility, 14 respondents accounting for $17.5 \%$ indicated very important as an answer, 7 chose somewhat important, 6 indicated neutral, 21 accounting for $27.5 \%$ of the respondents chose not important and 32 respondents representing $40 \%$ chose not at all important. The item recorded a mean ranking of 1.4 which indicates that respondents were of the view that career opportunity is not an important factor in determining employee retention in the University. On the question of whether good safety measures put in place by the University accounts for employee retention, 18 respondents said it is a very important factor, 27 indicated that it is important, 13 were neutral, 10 indicated not very important and 12 indicated not at all important. The mean rank of 3.4 indicates that respondents agree in the statement that good safety measures accounts for retention of employees in the University.

Job security as one of the factors that account for employee retention recorded 10 as very important, 31 as somewhat important, 11 as neutral, 15 as not very important and 17 as not at all important. The item recorded a mean rank of 3.2 which indicates that respondents view job security as one of the factors that account for employee retention.

Accommodation as an important factor for employee retention was also put to test. Twenty-three (23) respondents representing $28.9 \%$ responded that it is a very important 
factor for their retention whilst 19 respondents accounting for $36.3 \%$ also indicated that accommodation was somewhat an important factor for employee retention. Accommodation and transportation are viewed as one of the factors that lead to employee retention. This is indicated by the mean 3.1 recorded by the item.

The result from Table 4 indicates that among the factors that determine employee retention in PUG, the four (4) topmost variables are positive with mean rank of 4.0 ; health and other benefits, mean rank of 3.8; leave benefits, a mean rank of 3.5 and good safety measures, a mean rank of 3.4.

\subsubsection{Intrinsic Motivational Factors That Encourage Employees Retention}

The researchers formulated a 5-item statement to test the intrinsic motivational factors that lead to employee retention at PUG.

Table 4. Intrinsic motivational factors that lead to employee retention.

\begin{tabular}{|c|c|c|c|c|c|c|c|}
\hline \multirow{2}{*}{ Intrinsic motivational factors } & \multicolumn{5}{|c|}{ Number/Frequency } & \multirow{2}{*}{$\overline{\boldsymbol{x}}$} & \multirow{2}{*}{ Decision } \\
\hline & 5 & 4 & 3 & 2 & 1 & & \\
\hline Considering everything, to what extent are you satisfied with your job & $(12.0)$ & $(14.0)$ & $(13.0)$ & $(20.0)$ & $(21.0)$ & 2.7 & Very Important \\
\hline Considering everything, to what extent are you satisfied with your organisation & $(24.0)$ & $(21.0)$ & $(7.0)$ & $(18.0)$ & $(10.0)$ & 3.8 & Very Important \\
\hline I feel I belong to an organisation and I am a valuable member & $(41.0)$ & $(22.0)$ & $(8.0)$ & $(7.0)$ & $(2.0)$ & 4.2 & Very Important \\
\hline My work gives me a feeling of personal satisfaction & $(22.0)$ & $(28.0)$ & $(8.0)$ & $(12.0)$ & $(10.0)$ & 3.5 & Very Important \\
\hline There is emphasis on getting problems solved rather than ignoring them. & $(12.0)$ & $(15.0)$ & $(14.0)$ & $(22.0)$ & $(17.0)$ & 2.8 & Very Important \\
\hline
\end{tabular}

Source: Fieldwork, 2020.

NOTE: $5=$ To a very large extent, $4=$ To a large extent, $3=$ Undecided, $2=$ To a moderate extent, $1=$ To a small extent $) ; \mathrm{X}(1.00-2.50-$ large extent; $2.60-$ 5.00 - a moderate extent).

Table 4, presents intrinsic motivational factors that promote employee's retention at PUG. On the question "considering everything, to what extent are you satisfied with your job", it was deduced that 12 respondents representing $15 \%$ answered to a very large extent, 14 indicated to a large extent, 13 were undecided, 20 respondents accounting for $25 \%$ indicated to moderate extent" and 21 , which also represented $26.3 \%$ pointed to a very small extent. A mean rank of 2.7 indicates that to a large extent respondent were of the view that they were satisfied with their job.

Item 2 on this research question reads "to what extent are you satisfied with your organization". Table 4 again, shows that 24 of the subjects, representing $30 \%$ indicated to very large extent and 21 respondents that also accounted for $26.3 \%$ indicated" to a large extent. On the other hand, 7 respondents were undecided, $22.5 \%$ (18) indicated to a moderate extent" and 10 respondents that accounted for $12.5 \%$ indicated", to a small extent to item 2 .

Item 3 had 41 respondents representing 51.3\% indicating that to a very large extent they feel they are valuable members of the Institution. Twenty-two (22) respondents accounting for $27.5 \%$ indicated to a large extent, 8 respondents accounting for $10 \%$ were undecided, 7 indicated to a large extent whilst 2 respondents indicated to a small extent. The mean rank of 4 indicates that to a large extent respondent feel they are valuable members of the Institution.

Item 4 made a statement to indicate that the staff feel that they belong to an organisation and that they are valuable members within the institution. The response obtained pointed out that majority of the respondents (41) representing $51.3 \%$ asserted that to a very large extent, they feel part of the institution and that they are valuable members of the institution. Twenty-two (22) respondents representing 27.5 also indicated to a large extent to item 3 whilst 8 and 7 respondents indicated undecided and to a moderate extent respectively. The mean rank of 4 for item 3 indicated that the staff of PUG feel very important to the institution.

The feeling of personal satisfaction in relation to the work performed by the respondents was also put to test. The response provided indicated that 22 respondents agree to a very large extent that their work gives them a feeling of personal satisfaction. The staff that agreed to a large extent were 28 representing $35 \%$ whilst 8 and 12 respondents were neutral and agreed to a moderate extent respectively. The mean rank for item 4 is 3.5 which means that the work done by the respondents gives them personal satisfaction to a moderate extent.

To test the intrinsic motivational factors that lead to employee retention, the researchers indicated the level of agreement to the statement; 'there is emphasis on getting problems solved rather than ignoring them'. The data obtained pointed that 12 respondents indicated to a very large extend whilst 15 respondents representing 18.85 indicated to a large extent. The respondents that indicated 'undecided' and 'to a moderate extent to the statement were $14(17.5 \%)$ and $22(27.5 \%)$ respectively. On the other hand, 17 respondents representing $21.3 \%$ indicated that to a small extent there is emphasis on getting problems solved rather than ignoring them. The mean rank for this item is 2.78 which shows that emphasis on getting problems solved rather than ignoring them is a very important intrinsic factor to employee retention.

\subsection{Discussions}

\subsubsection{Extrinsic Motivational Factors That Encourage Workers Retention}

This research question was formulated to ascertain evidence regarding the type(s) of extrinsic motivational factors that encourage employee satisfaction and retention at PUG. These types of extrinsic motivations received had a large influence on the level of employee satisfaction and retention. The evidence gathered showed that salary, wages, 
promotion, position, leave benefits, retirement plan, health benefit, good safety measures, job security, accommodation and transportation were the motivational factors that encourage employee retention. Salary and wages received a mean rank of 2.9 indicating that the respondents were of the view that monetary issue accounts for employee retention in the University. It also became evident that thirty-four (34) respondents representing $42.5 \%$ of the respondents asserted that promotion is very important. Promotion attained a mean rank of 3.3 which implies that promotion is one of the extrinsic factors that accounts for employee retention. It was further revealed that 31 of the respondents indicated that position is a very important extrinsic factor that influenced staff retention. Thirty-two (32) of the respondents also indicated that position was somewhat important accounting for $40 \%$ of the respondents to employee retention. Position had a mean ranking of 4.0 which demonstrated that position is an important extrinsic factor that needs to be given attention in employee retention.

The data obtained also revealed that leave benefit is another intrinsic factor that motivates employee retention at PUG. Twenty-two (22) staff representing 27.5\% indicated that leave benefit was very important. Again, 28 staff that accounted for $35 \%$ of the respondents pointed out that leave benefit was somewhat important. Leave benefit obtained a mean rank of 3.5 which indicated that leave benefits is one of the important extrinsic factors that lead to employee retention. On the issue of retirement plan, it was revealed that it was not very important to 22 respondents whilst 17 indicated not at all important. The item recorded a mean rank of 2.8 which implies that the respondents were of the view that retirement plan are necessary factors in determining if an employee will remain in the employment. Health and other benefits were also revealed to be other intrinsic motivational factors that motivate employees' retention at PUG. Health and other benefits received a mean rank of 3.8 which indicates that good health plan and other benefits employees receive account for the employee retention in the Institution. Forty-five (45) respondents accounting for $56.3 \%$ of the respondents indicated that health and other benefits were very important to employee retention whilst $8.8 \%$ and $7.5 \%$ indicated that health and other benefits were respectively not their concern and not at all important to their retention at their work place. On the question of whether good safety measures put in place by the University accounted for employee retention, 18 respondents said it is a very important factor which recorded a mean rank of 3.4 indicating that respondents agreed with the statement that good safety measures account for retention of employees in the University. Job security was one of the factors that motivated employee retention at PUG which recorded 31 respondents indicating that it is somewhat important. The job security as an intrinsic motivational factor for employee retention obtained a mean rank of 3.2 which indicates that respondents view job security as one of the factors that accounts for employee retention. Accommodation was also ascertained as an important factor for employee retention. Twenty-three
(23) respondents representing $28.9 \%$ responded that it is a very important factor for their retention whilst 19 respondents accounting for $36.3 \%$ also indicated that accommodation was somewhat an important factor for employee retention. Accommodation and transportation indicated a mean rank of 3.1 which demonstrates that accommodation and transportation are an important motivational factors for employee retention at PUG.

The evidence obtained indicated that among the factors that determine employee retention in PUG, the four topmost variables were position (positive mean rank of 4.0); health and other benefits (positive mean rank of 3.80); leave benefits (mean rank of 3.5); good safety measures (a mean rank of 3.4); promotion (positive mean rank of 3.3); job security (mean rank of 3.2) and accommodation and transportation (positive mean rank of 3.1).

The evidence produced above confirms the work [17]. Again, according to, [17] asserted that extrinsic motivation has typically been characterized as a pale impoverished (even if powerful) form of motivation that contrasts with intrinsic motivation. According to [18] an extrinsically motivated employee is driven by tangible rewards - money, gifts, social approval; they are driven specifically to avoid punishments getting fired, rejection, being passed over for an important project, and career limiting responses.

\subsubsection{Intrinsic Motivational Factors That Encourage Workers to Stay on Their Jobs}

The researchers formulated a 5-item statement to test the intrinsic motivational factors that lead to employee retention at PUG. On the question "considering everything, to what extent are you satisfied with your job" it was revealed that 20 respondents accounting for $25 \%$ indicated to moderate extent and 21 which also represented $26.3 \%$ pointed to a very small extent. A mean rank of 2.7 indicates that to a large extent respondent were of the view that they were satisfied with their job. The question "to what extent are you satisfied with your organization" was put before the respondents. The evidence obtained shows that 24 of the subjects representing $30 \%$ indicated they were satisfied to very large extent and 21 respondents that also accounted for $26.3 \%$ indicated to a large extent they are satisfied with PUG. Forty-one (41) respondents accounting for $51.3 \%$ indicated that to a very large extent they feel they are valuable members of PUG. Twenty-two (22) respondents accounting for $27.5 \%$ indicated to a large extent they feel they are valuable to PUG. The mean rank of 4.2 obtained indicates that to a large extent respondent feel they are valuable members of the organization. Statement to indicate that the staff feel that they belong to an organisation and that they are valuable members within the institution revealed that majority of the respondents (41) representing 51.3\% asserted that to a very large extent, they feel part of the institution and that they are valuable members of the institution. The mean rank of 4.2 indicated that the staff of PUG feel very important to the institution.

The evidence ascertained indicated that 22 respondents 
agree to a very large extent that their work gives them a feeling of personal satisfaction. The staff that agreed to a large extent were 28 representing $35 \%$. The mean rank for item 4 is 3.5 means that the work done by the respondents gives them personal satisfaction to a moderate extent.

The evidence gathered pointed that 12 respondents indicated to a very large extend 'there is emphasis on getting problems solved rather than ignoring them' whilst 15 respondents representing 18.85 indicated to a large extent. The mean rank for this item is 2.78 which points that emphasis on getting problems solved rather than ignoring them is a very important intrinsic factor to employee retention. The evidence obtained agrees with the works of [19] who pointed out that those intrinsic factors such as achievement, recognition, the work itself, responsibility and advancement seem to be related to job satisfaction. The study also confirms the works of [20] who stated that employers usually administer rewards in the form of praising a committed employee, provision of fringe benefits and recognition. According to authors intrinsic rewards are selfadministered. They consist of how employees feel about an objective accomplished. Attention is being drawn here to the fact that behavior stems from within an individual. This work also lends credence to the study conducted by [20]. According to him, [20] intrinsic motivation is "what people do without external inducement". The authors further asserted that Hunger, a sense of duty, altruism, and a desire to feel appreciated are examples of intrinsic motivation. The above evidence presents important information for this study. From the above discussions, it is evidenced that there are number of both intrinsic and extrinsic motivational factors at the PUG. If it is therefore subsequently established despite all these benefits and motivational factors employees still want to leave the institution, then it can be concluded that both intrinsic and extrinsic motivation and benefits have no influence on the retention of staff.

\subsubsection{The Relationship Between Employee Motivation and Retention}

The relationship between motivation and employee retention was also ascertained through the study. The evidence gathered pointed that majority of the respondents disagreed that they feel like leaving the institution because of too much work. Majority of the respondents also disagreed that their work negatively affected their personal lives. The respondents that disagreed with the statement were 28 accounting for $35 \%$ whilst $31.5 \%$ were not sure of the effect of their work on their personal lives. The evidence obtained clearly depicted that majority of the staff at PUG have not considered leaving their current employer. The respondents who had not considered leaving PUG were 42 representing $52.5 \%$ whilst 28 had considered leaving PUG.

It was revealed through the study that salary was a very big motivating factor to most of the staff of PUG. The respondents that strongly agreed that they felt cheated in their salary were 26 accounting for $32.5 \%$. However, 32 respondents representing $40 \%$ also agreed that they felt cheated with their salaries/wages. The evidence gathered and discussed above establishes that majority of the staff of PUG do not wish to leave the institution. As earlier revealed, there are a lot of intrinsic and extrinsic motivational factors at PUG. It can therefore be established that both intrinsic and extrinsic motivation affect employee retention in an organization or an institution.

\subsubsection{Management View on the Effect of Intrinsic and Extrinsic Motivation on Staff Retention}

These were the responses found during the interview with management as regards staff opinion on how intrinsic and extrinsic motivation affect their retention. According to them, to enhance staff retention in PUG, there should be proper and improved retirement benefits for staff such as "Provident Scheme" in addition to the Ex-gratia to serve as motivation to staff. Again, the University is making promotion of staff less cumbersome to avoid rigid procedures that discouraged staff from putting up their best. Furthermore, study leave with pay encourages staff who qualified, to upgrade themselves in their areas of work schedule so as to improve upon their careers. Adequate opportunities for staff training and development are encouragement for staff who want to upgrade themselves through seminars, workshops and short courses as a form of motivation to staff. This aspect of training opportunities is reserved for staff who will not be able to attend formal education and have special skills to remain on the job. According to the selected Management members interviewed, recognition of hard work commensurate with reward systems of PUG and that Management usually consult workers' unions and departmental heads to present employees who excel in their job schedules for rewards. This kind of motivation encourages other employees to also work hard to earn recognition in the Institution. In most cases such employees are honored on occasions like congregations and forums organized by the University. They are in most cases given citations, incremental jumps on their salaries and sometimes approve of a study leave with pay. Then, on the causes, they all mentioned that lack of training and development, poor management style, desire for job change, low pay, lack of promotion and poor working conditions.

\section{Conclusion}

The main objective of this study was to determine intrinsic and extrinsic factors that make employees stay put at their job at PUG. This work presents conclusions of the study as follows:

1. Extrinsic Motivation of staff in PUG influences Employee Retention. Evidence gathered from the study showed that salary, wages, promotion, position, leave benefits, retirement plan, health benefit, good safety measures, job security, accommodation and transportation were strong motivational factors that encourage employee retention. The evidence obtained indicated that among the extrinsic factors that determine 
employee retention in PUG, the topmost variables were position (positive mean rank of 4.0 ); health and other benefits (positive mean rank of 3.80); leave benefits (mean rank of 3.5); good safety measures (a mean rank of 3.4); promotion (positive mean rank of 3.3); job security (mean rank of 3.2) and accommodation and transportation (positive mean rank of 3.1).

2. Intrinsic Motivational Factors that encourage Employees Retention at PUG are satisfaction with job, satisfaction with the institution or organization, feeling of being valuable to PUG and nature of their work gives them a feeling of personal satisfaction.

3. The main result of this study is strong support for claims that both intrinsic and extrinsic motivation can significantly increase employee retention rate when they are carefully implemented. Intrinsic and extrinsic motivation are thus important factors that explain certain job aspects that contribute significantly to the institution, such as, job satisfaction. However, the best conclusion from this analysis is that, regardless of the kind of performance benefit management is attempting to realize, both intrinsic and extrinsic motivation appear to be beneficial.

\section{References}

[1] Alonso, Pablo, and Gregory B. Lewis. 2001. "Public Service Motivation and Job Performance: Evidence from the Federal Sector." American Review of Public Administration 31: 36380 .

[2] Battaglio, R. Paul, Jr. 2009. "Privatization and Citizen Preferences: A Cross-National Analysis of Demand for Private versus Public Provision of Services in Three Industries." Administration \& Society 41: 38-66.

[3] Battaglio, R. Paul, Jr. 2010. "Public Service Reform and Motivation: Evidence from an Employment At-Will Environment." Review of Public Personnel Administration 30: 341-63.

[4] Battaglio, R. Paul, Jr., and Stephen E. Condrey. (2006). "Civil Service Reform: Examining State and Local Cases.” Review of Public Personnel Administration 26: 118-38.

[5] Battaglio, R. Paul, Jr., and Stephen E. Condrey. 2009. "Reforming Public Management: Analyzing the Impact of Public Service Reform on Organizational and Managerial Trust." Journal of Public Administration Research \& Theory 19: 689-707.

[6] Castaing, S. 2006. The effects of psychological contract fulfilment and public service motivation on organizational commitment in the French civil service. Public policy and administration, 21 (1): 84-98.
[7] Baron, R. M. and Kenny, D. A. 1986. The moderator-mediator variable distinction in social psychological research: conceptual, strategic and statistical considerations. Journal of personality and social psychology. 51 (6): 1173-1182.

[8] netta Weinstein, Edward 1. deci, Richard m. ryan (2011) motivational determinats of integrating positive and negative past identities, journal of personality and social psychology 1050,85 .

[9] Lisa Legault, Isabelle Green-Demers, Protius Grant, Joyce Chung 92007) on the self-regulation of Imlicit and Explicit prejudice A Self-Determination Theory perspective. 158 (67).

[10] Siyuan Miao, Jachoon Rhee, In Jun (2020) how much does extrinsic motivation or intrinsic motivation affect job engagement or turnover intention, a comparison study in China. (MDPI) sustainability, 12, 3630. Doi: 10.3390/su12093630.

[11] Behn, R. D. 1995. The big questions of public management. Public administration review. 55 (4): 313-324.

[12] Brewer, G. A. and S. C. Selden. 1998. Whistle blowers in the federal civil service: new evidence of the public service ethic. Journal of public administration research and theory. 8 (3): 413-439.

[13] Mosad zineldin (2000) Total relationship management, student literature ISBN; 914401273X, 978144012736 LENGTH: 296 pages.

[14] Daniel Eseme Gberevbie (2010), Strategies for employee recruitment, retention and performance: Dimension of the Federal civil service of Nigeria (j) African Journal of Business Management Vol. 4 (8), pp. 1447-1456, online at http://ww w.academicjournals.org/AJBM ISSN 1993-8233 $\quad$ C2010 Academic Journals.

[15] Claybaugh, Zach. Research Guides: Organizing Academic Research Papers: Types of Research Designs." library.sacredheart.edu. Retrieved 2020-10-28.

[16] Wright, Sarah; O'Brien, Bridget C.; Nimmon, Laura; Law, Marcus; Mylopoulos, Maria (2016). Research Design Considerations." Journal of Graduate Medical Education. 8 (1): 97-98. doi: 10.4300/JGME-D-15-00566.1. ISSN 19498349. PMC 4763399. PMID 26913111.

[17] [CrossRef] 8. Fehr, E.; Herz, H.; Wilkening, T. (2013) The lure of authority: Motivation and incentive effects of power. Am. Econ. Rev, 103, 1325-1359.

[18] Certo, S. C. (2000). Modern Management: Diversity, quality ethics and the global Environment, $\left(8^{\text {th }}\right.$ ed). New Jersey: Upper Saddle River.

[19] Schaufeli, W. B.; Bakker, A. B. (2020) Job demands, job resources, and their relationship with burnout and engagement: A multi-sample study. J. Organ. Behav. 2004, 25, 293-315. [CrossRef] Sustainability, 12, 363016 of 187.

[20] Murdock, K. Intrinsic motivation and optimal incentive contracts. RAND J. Econ. 2002, 33, 650-672. 